\title{
PRIMEIRAS EXPERIÊNCIAS DA EDUCAÇÃO DO CAMPO NO PROGRAMA RESIDÊNCIA PEDAGÓGICA
}

First experiences of field education in the Pedagogical Residence Program

Primeras experiencias de educación del campo en lo Programa residencia pedagógica

\section{Aparecida de Jesus Soares Pereira ${ }^{* 1}$, Waldir Pereira da Silva ${ }^{1}$, Mirian} Ferreira da Cunha ${ }^{1}$, Rúbia Araújo Silva ${ }^{1}$

${ }^{1}$ Laboratório de Educação Musical, Curso de Licenciatura em Educação do Campo, Universidade Federal do Tocantins-UFT, Arraias -TO, Brasil.

*Correspondência: Curso de Licenciatura em Educação do Campo, Universidade Federal do Tocantins - UFT, Campus Professor Dr. Sérgio Jacintho Leonor, Av. Juraíldes de Sena e Abreu, Setor Buritizinho/ sala 10 - Bloco Bala, Arraias - Tocantins, Brasil.CEP:77.330-000.e-mails: cida.soares@uft.edu.

\section{Artigo recebido em 03/04/2020 aprovado em 09/04/2020 publicado em 17/04/2020.}

\section{INTRODUÇÃO}

O período da Residência Pedagógica foi propício para a estreita relação entre as teorias estudadas na Universidade e a prática educativa colocada em ação. O Programa contribuiu para desenvolver o pensar acerca da educação e a ação em sala de aula. É justamente neste momento que se vivencia a realidade exposta nos diversos espaços educacionais, os desafios, as dificuldades que as instituições de ensino formal e informal passam para conseguir oferecer uma educação de qualidade. $\mathrm{O}$ Programa Residência Pedagógica tem como objetivos fazer com que os discentes possam vivenciar a sala de aula, obter maior compreensão da realidade, familiarizar com o currículo de ensino, a observação do espaço de estágio, o reconhecimento do público, o planejamento de aulas e demais atividades e a ação educativa em sala de aula.

Segundo a Coordenação de Aperfeiçoamento de Pessoal de Nível Superior (CAPES), é uma Política Nacional de Formação de Professores que integram a Política Nacional de Formação de Professores e tem por objetivo induzir o aperfeiçoamento da formação prática nos cursos de licenciatura, promovendo a imersão do licenciando na escola de educação básica, a partir da segunda metade de seu curso. (CAPES, 2020). Ainda segundo a Fundação CAPES, o objetivo é a consolidação da prática educativa pelo discente, avaliado pelo educador regente. Para a fundação CAPES, é uma ação articuladora, conforme descreve em sua página, a saber:

\begin{abstract}
A Residência Pedagógica, articulada aos demais programas da Capes compõem a Política Nacional tem como premissas básicas o entendimento de que a formação de professores nos cursos de licenciatura deve assegurar aos seus egressos, habilidades e competências que lhes permitam realizar um ensino de qualidade nas escolas de educação básica. (CAPES, 2020)
\end{abstract}

Como Política Nacional, o programa coordenado pela Fundação CAPES, promove uma maior interação de saberes científicos mediados nas universidades e a prática pedagógica em sala de aula. Uma dialógica entre duas realidade de ensino, que envolve teoria e prática de ensino voltado neste contexto, para a Educação do Campo. 


\section{METODOLOGIAS E MATERIAIS}

No contexto do Residência Pedagógica, foram utilizados alguns passos importantes para alcançar o êxito da prática educativa dos discentesresidentes em formação acadêmica do Curso de Licenciatura em Educação do Campo - Códigos e Linguagens Artes Visuais e Música da Universidade Federal do Tocantins - UFT em Arraias - TO, entre eles, destacam: reconhecimento do espaço campo de prática educativa, agendamento de visitas e observações, início de ações práticas e/ou educativas, escolha da ação de intervenção pedagógica, conteúdos, oficinas, etc., planejamentos das aulas e projetos, prática de intervenção educativa e produtiva, avaliação e elaboração de relatórios.

Nas ações foram realizadas oficinas de Arte com pintura utilizando materiais como terra, açafrão, cola, café e outros para produzir as cores e assim realizar as pinturas. Nas oficinas de Música foram trabalhados os conceitos da musicalidade, sons, letra, mensagem, contexto e gênero musical. Com isto percebe-se uma grande conquista, pois as escolas têm apoiado estas práticas e valorizado as ações pedagógicas em relação às Artes, especificamente o ensino de música nas escolas do campo, o que caracteriza o início da inserção desta modalidade de ensino no contexto escolar do campo que tem tornado o ensino mais prazeroso, motivador e de qualidade, $\mathrm{e}$ de certa forma, uma garantia de sucesso e permanência do educando na escola e consequentemente espera-se a consolidação dessa modalidade como conteúdo pelo seu valor e sua necessidade na formação humana, conforme vários pesquisadores e educadores têm destacado em diversas pesquisas.

De modo geral, foi uma conquista, mas ainda há muitos caminhos a percorrer para manter e trazer ainda mais melhorias para a educação campesina.

Atualmente a Educação do Campo apresenta uma identidade mais concreta do ponto de vista dos debates, das pesquisas, das mudanças nas legislações educacionais, nas exigências de deveres a serem cumpridos pelo Estado, sociedade e instituições de ensino. E isso está explícito na concepção de educação do campo, no pensar de Kolling; Nery; Molina, (1999), que destacam;

[...] o propósito é conceber uma educação básica do campo, voltada aos interesses e ao desenvolvimento sociocultural e econômico dos povos que habitam e trabalham no campo, atendendo às suas diferenças históricas e culturais para que vivam com dignidade e para que, organizados, resistam contra a exclusão, ou seja, este do campo tem o sentido do pluralismo das idéias e das concepções pedagógicas. (KOLLING; NERY; MOLINA, 1999, p. 28-29)

A Educação do Campo passa a assumir um papel significativo na vida camponesa, desse modo, ela pretende promover o sentimento de pertencimento do homem em seu espaço, e deve trabalhar para isso, pois sem esta visão, a mesma não terá nenhum sentido transformador. O que se espera da formação do educador é que ele tenha condições de ir além do convencional, das práticas educativas costumeiras, perpassando os viés do ensino que não vê no homem suas demandas e anseios, passando a compreendê-lo em seu contexto, promovendo em si, a reflexão crítica capaz de fazer com que o mesmo possa evoluir e progredir em seu espaço de vivências, como destaca Franco (2002), um curso de formação deve ir além do que já estamos acostumados a observar ao logo da história da educação.

Um curso de formação de professores não se efetua no vazio, devendo estar vinculado a uma intencionalidade, a uma política, a uma epistemologia, a pesquisas aprofundadas dos saberes pedagógicos. A formação de professores desvinculada de um projeto político só pode caracterizar uma concepção extremamente pragmatista, reprodutivista, tecnicista da ação docente. (FRANCO 2002, p. 177). 
Desse modo, o Residência Pedagógica proporciona rever velhos conceitos, analisar a realidade, compreender as relações homem-espaço, a dinâmica cultural, social, ambiental e econômica, para assim, mediar a prática de aprendizagem significativa em sala de aula.

\section{RESULTADOS E DISCUSSÃO}

A formação em Educação do Campo pela Universidade Federal do Tocantins - Campus de Arraias - TO, promoveu uma dialógica entre teoria e prática, dando ênfase pela dinâmica do Programa Residência Pedagógica, consolidando uma formação acadêmica voltada para as reflexões acerca do ensino para o homem do campo, nesta perspectiva, habilitando seus acadêmicos ao exercício pleno da prática educacional em sala de aula.

$\mathrm{Na}$ concepção de estágio supervisionado, a prática pedagógica exige um olhar atento ao espaço de relações de aprendizagens, sem uma visão preconceituosa da realidade, mas buscando compreender a realidade, moldando o perfil de projeto de ensino capaz de promover um ensino libertador.

\section{CONCLUSÃO}

Ao longo do Residência Pedagógica percebeuse que há ainda alguns desafios a serem superados, entre eles destacam; a) muitas escolas urbanas atendem um grande número de alunos do campo, isso devido ao fechamento de escolas rurais, b) muitos educadores ainda não tiveram formação voltada para o público do meio rural, especificamente na área das Artes, c) currículos referenciais e projetos de ensino não estabelecem práticas educativas com ênfase nas especificidades do campo, d) o jovem do campo está deixando suas comunidades em busca de novas perspectivas, inclusive trabalho, porque as políticas públicas educacionais, culturais, econômicas não conseguem mantê-lo no seu espaço de vivência. De modo geral, as escolas que ainda existem e que estão em pleno funcionamento no meio rural, ainda não têm uma educação do campo voltada para o homem camponês, tendo sua prática moldada no perfil das demais urbanas. Cabe ao Estado rever suas políticas públicas, aos educadores e instituições de ensino refletirem e atuarem melhor nos problemas e demandas que ainda persistem em enfraquecer as vivências do homem do campo, neste contexto, promover e fazer com que o seu sentimento de pertencimento ao campo seja fortalecido pela educação, pela cultura e pelos programas de apoio às atividades camponesas, em especial as famílias de pequenos agricultores.

\section{AGRADECIMENTOS}

À Fundação Coordenação de Aperfeiçoamento de Pessoal de Nível Superior - CAPES. À Universidade Federal do Tocantins - Campus de Arraias - TO. AO Curso de Licenciatura em Educação do Campo - Artes Visuais e Música. Ao Colégio Estadual Irany Nunes do Prado (equipe gestora, alunos, professores e funcionários administrativos pela receptividade).

Todos os autores declararam não haver qualquer potencial conflito de interesses referente a este artigo.

\section{REFERÊNCIAS}

COORDENAÇÃO DE APERFEIÇOAMENTO DE PESSOAL DE NÍVEL SUPERIOR - CAPES.

Programa de Residência Pedagógica. Disponível em: https://www.capes.gov.br/educacaobasica/programa-residencia-pedagogica. Acesso em 2 de janeiro de 2020.

FRANCO, Maria Amélia Santoro. Indicativos para um currículo de formação de pedagogos. In: ROSA, Dalva E. Gonçalves \& SOUZA, Vanilton Camilo de. (Org.). Políticas organizativas e curriculares, educação inclusiva e formação de professores. Rio de Janeiro: DP\&A, 2002.

KOLLING, Edgar Jorge; NERY, Israel José; MOLINA, Mônica Castagna. Por uma educação básica do campo: memórias. Brasília: Fundação Universidade de Brasília, 1999. v. 1. Revista Desafios - v. 7, n. Supl. RP-UFT, 2020 